\title{
Preparing Employees for the Learning Enterprise through Simulation Games
}

\author{
Sven Haferkamp, Siân Thomas, Klaus Henning \\ Institute for Entrepreneurial Cybernetics, Mülheim a. d. Ruhr, Germany
}

E-mail:SHA@mailgate.agiplan.de

Key words: Management Game, Learning Enterprise, Quality Management, Cybernetics, Board Game

\begin{abstract}
In order to cope with the challenges of current markets, enterprises need to be technically as well as socially capable of development. The necessary ability of innovation for structural and process adaptation can be achieved through the key competence of learning capability (Reinhardt/Pawlowsky, 1998). Instruments for the practical support of learning processes in enterprises are becoming increasingly important in this context.

Simulation games can prove to increase the learning capability of groups and teams of employees, and to stimulate organisational learning processes (Heidack, 1995). The aim of this paper is to present a three-level-model of learning processes within a simulation game. The model is based on "feedback" structures, which are also used in the field of entrepreneurial cybernetics for the control of enterprise processes. According to Argyris \& Schön (1978), these feedback structures consist of the following three processes: result-oriented learning (Single-Loop Learning), experienceoriented learning (Double-Loop Learning) and process-oriented learning (Deutero Learning).

The practical application of the model will be explained using the board game "Q-Key - Quality Management". It supports enterprises in the implementation of TQM-models by promoting quality-awareness and motivation among employees. The game offers the possibility of simultaneously promoting social, methodical and knowledge competencies among employees (Heidack, 1995). The board game "Q-Key" can convey abstract Quality Management concepts in a clear and "living" way, which leads to these concepts being successfully transferred into day-to-day life within enterprises.
\end{abstract}




\section{INTRODUCTION}

In order to cope with the challenges of current markets, enterprises need to be technically as well as socially capable of development. The necessary innovative ability for structural and process adaptation can be achieved through the key competence of learning capability (Reinhardt/Pawlowsky, 1998). Instruments for the practical support of learning processes in enterprises are becoming increasingly important in this context.

Simulation games can prove to increase the learning capability of groups and teams of employees, and to stimulate organizational learning processes (Heidack, 1995). The aim of this paper is to present a three-level-model of learning processes within a simulation game. The model is based on "feedback" structures, which are also used in the field of entrepreneurial cybernetics for the control of enterprise processes. According to Argyris \& Schön (1978), these feedback structures consist of the following three processes: Single-Loop Learning, Double-Loop Learning and processoriented learning (or Deutero Learning).

The practical application of the model will be explained using the board game "Q-Key - Quality Management". The board game "Q-Key" supports enterprises in the implementation of TQM-models by promoting qualityawareness and motivation among employees. The form of the board game offers the possibility of simultaneously promoting social, methodical and knowledge competencies among employees (Heidack, 1995). The board game "Q-Key" can convey abstract Quality Management concepts (from DIN ISO 9000 to TQM) in a clear and "living" way, which leads to these concepts being successfully transferred into day-to-day life within enterprises. The main advantage of Q-Key is that it supports the learning abilities of groups and teams, preparing them for the participative development of their specific QM-System.

\section{LEARNING LEVELS IN THE SIMULATION GAME}

In order to become "Learning Enterprises", companies and large enterprises in Germany are introducing enterprise simulation games in order to train and further educate their employees. In the foreground are learning concepts which give the employees increasingly important abilities (IfU, 1998). These include dealings with interlocking, multi-level decision processes, as well as co-operative work in sector-comprehensive and hierarchy-comprehensive work groups. 
The essential advantage of the simulation game method lies in the close linking together of actions (or rather decisions, whether it be alone or in teams) and learning. In contrast to the passive conveying of knowledge, the player has the opportunity to immediately use this acquired knowledge and, moreover, to receive feedback. The simulation game offers the participants a creative "playing field" which is beneficial to learning, in which they can gather experiences in dealing with problem or crisis situations.

Simulation games can vary in form and content, thus offering different learning contents. One of the most important features used to differentiate between these games are the various ways of processing and evaluating the decisions made by participants, that is, the model of the game. Here, a division into three varieties of simulation games can be made (Harrramach, 1992):

- Board games: Simulation games, which have the model of a board in the broader sense, for example a board, but also a blackboard, or a games table.

- Computer-based simulation games: Simulation games, which have the model of a computer simulation.

- Hand games: Simulation games, where the model is the person; although various other aids are used, the person and their behavior are the decisive elements of the game.

As computer-based simulation games are widely spread, the applicability of hand and board games within enterprises is often underestimated. These two varieties of simulation games can be of great benefit to employees in quite a practically-oriented way. Computer-based simulation games often lead to the problem that with most processes taking place in the background, the participants are often unable to detect or understand interdependencies and consequences (the so-called "black-box-syndrome"; Foerster 1993). By including optical and motoric elements into the learning process, which is often the case in board games and role-plays, the components of the game can be disclosed more comprehensibly than by mere "invisible" concepts and definitions.

The basic structure of the simulation game consists of the components of the action and reaction branches, and the flow of information between these branches (shown in Fig. 1).

The action branch of a simulation game is represented by the participants, who make their decisions based on the information available, and within the rules of the game. In addition, the game coordinator has the opportunity of giving the game participants orientation information, which is essential for the further course of the game. The decisions of the players trigger off reactions within the model of the simulation game. These decisions are 
transformed into corresponding results and effects, which in turn have repercussions on the participants. This transformation process can be implemented through the rules of a board game or role-play, or through a logical model in the case of a computer-aided simulation game. The transfer must ensure that experiences are used within a real system, in order to provide a reference to reality for the employees.

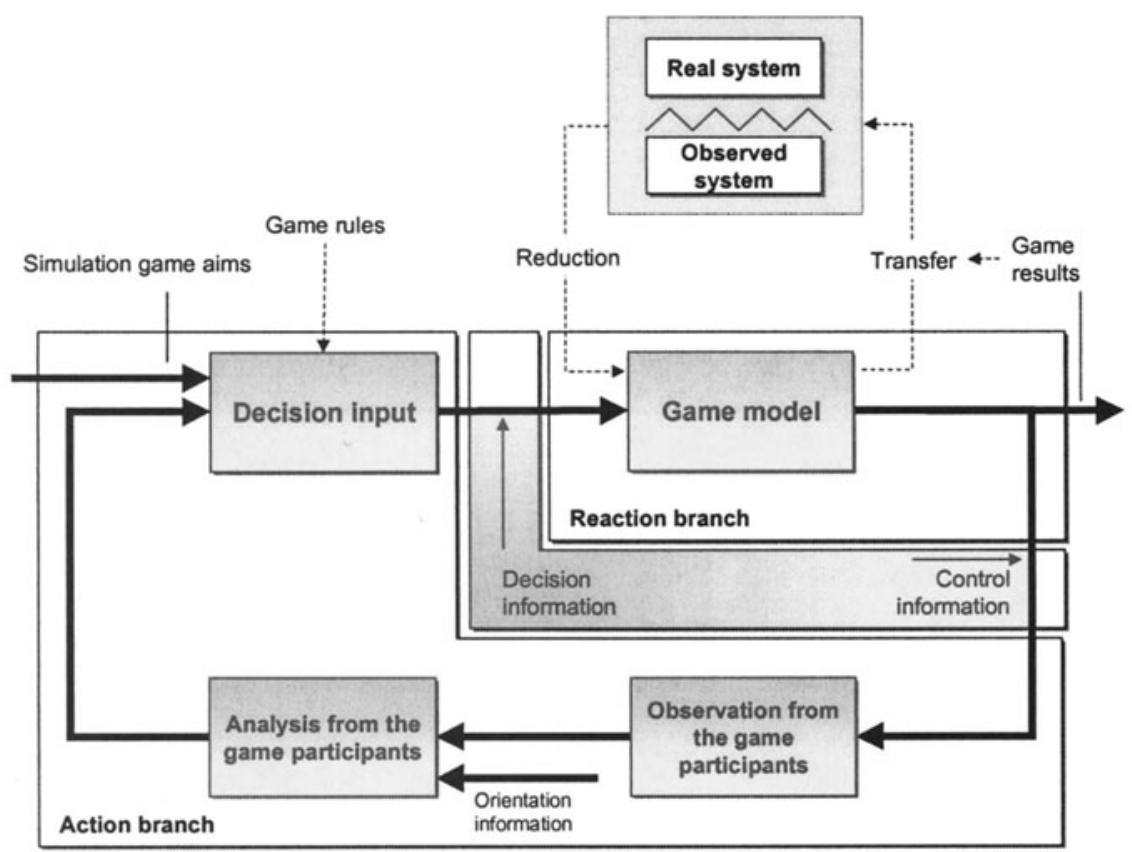

Figure 1. The structure of the board simulation game "Q-Key - Quality Management"

A three-level-model of the learning process in a simulation game can be built upon this basic structure (shown in Fig. 2; IfU 1998).

Under result-oriented learning, actions will be chosen which are in accord with the hypotheses about the game model, and, when needed, these will also be adapted. The learning process of experience-oriented learning, on the other hand, takes place when the experiences made during resultoriented learning lead to a change in the hypothesis of the game model. A result of such a fundamental change can be that the informational content represented in the game also gains a new structure (Probst/Büchel, 1994). An example would be the transition from a competitive to a co-operative situation, as is this case in many enterprise simulation games. 


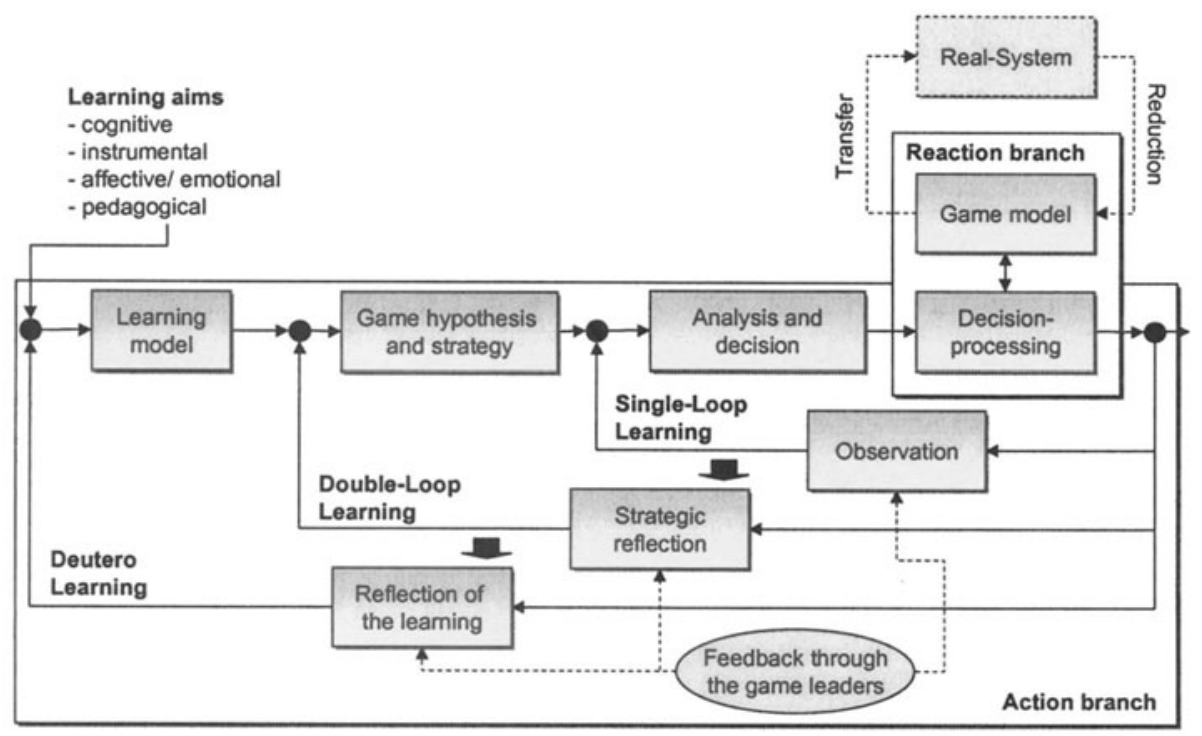

Figure 2. A three-level-model of the learning process in a simulation game

Transfer-oriented learning is a continuous process, during which the participants of the game make use of their experiences gained from the game model. It is only when real process learning takes place - when learning itself becomes the object of transfer - that real learning processes in the organization succeed. These are not confined to the simulation game, but rather they can be applied to the day-to-day problem situations within enterprises.

Another task of the game coordinator exists in the controlling of the course of the game along the three learning levels. In the transition from result-oriented to experience-oriented learning, the players should experience the so-called "Aha-experiences". Through this they learn how their action and decisions depend upon unconscious behavior and thought patterns. These hinder the players in their adaptation to changing situations, especially when they are no longer questioned. The assessment of transferoriented learning is most difficult and this process depends substantially on the competence and experience of the game coordinator (Reinhardt/ Pawlowsky, 1998). 


\section{AN EXAMPLE: Q-KEY - QUALITY MANAGEMENT}

The following shows a concrete example of how the three-level-model of the learning process can be used in a simulation game: the board game "QKey - Quality Management" (shown in Fig. 3).

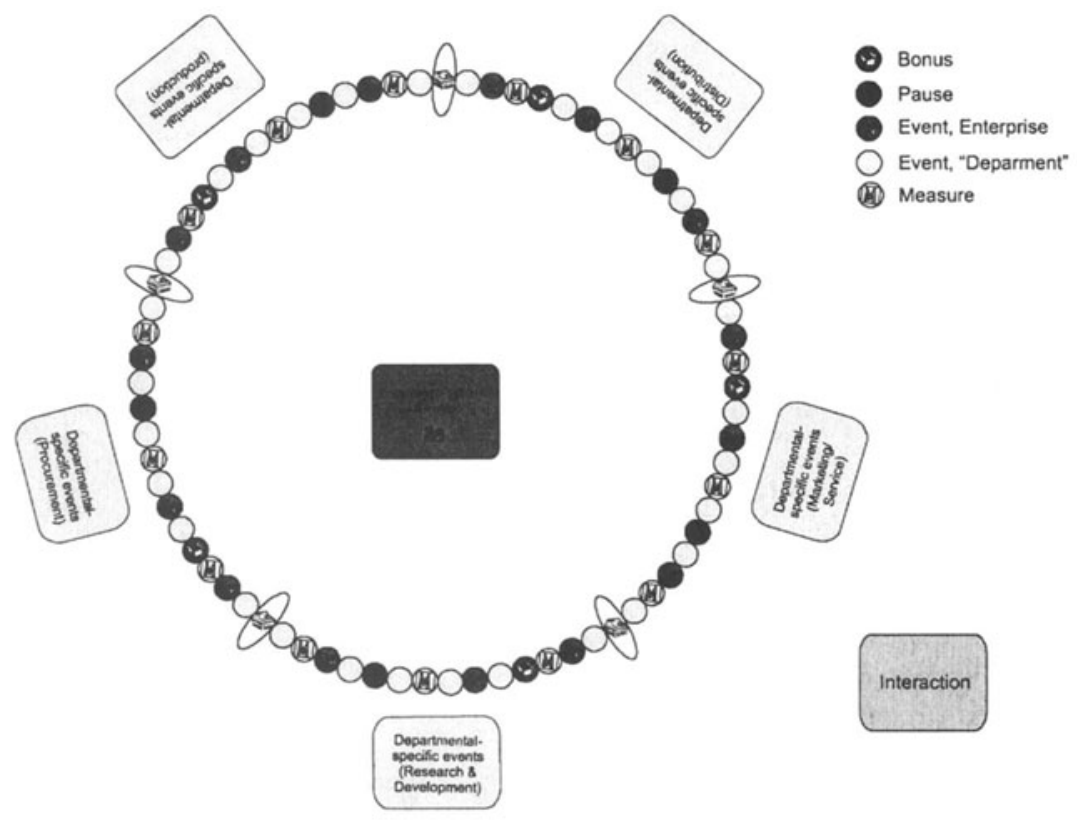

Figure 3. The board simulation game "Q-Key - Quality Management"

An example of the use of Q-Key within an enterprise was explored at a toy car manufacturing firm. This manufacturer had begun to introduce a $\mathrm{QM}$ system according to ISO 9001. This introductory phase would be completed with a successful certification audit.

The board game "Q-Key" supports enterprises in the introduction of quality-oriented measures by the promotion of quality-awareness and motivation among employees. The form of the board game offers the possibility of simultaneously promoting social, methodical and knowledge competencies among employees (Heidack, 1995). It can convey abstract QM concepts (from DIN ISO 9000 to TQM) in a clear and "living" way, and through this can be transferred successfully. Figure 4 shows the relationship between quality, time and costs (i. e. the so-called "magic triangle").

The target groups of Q-Key are participants in QM introduction teams, as well as employees in enterprises in general, who are to implement far- 
reaching QM measures. In both cases, a departmental-comprehensive crosssection of the enterprise should be guaranteed. The modular construction of the simulation game facilitates its use in a production-oriented, as well as a service-oriented enterprise.

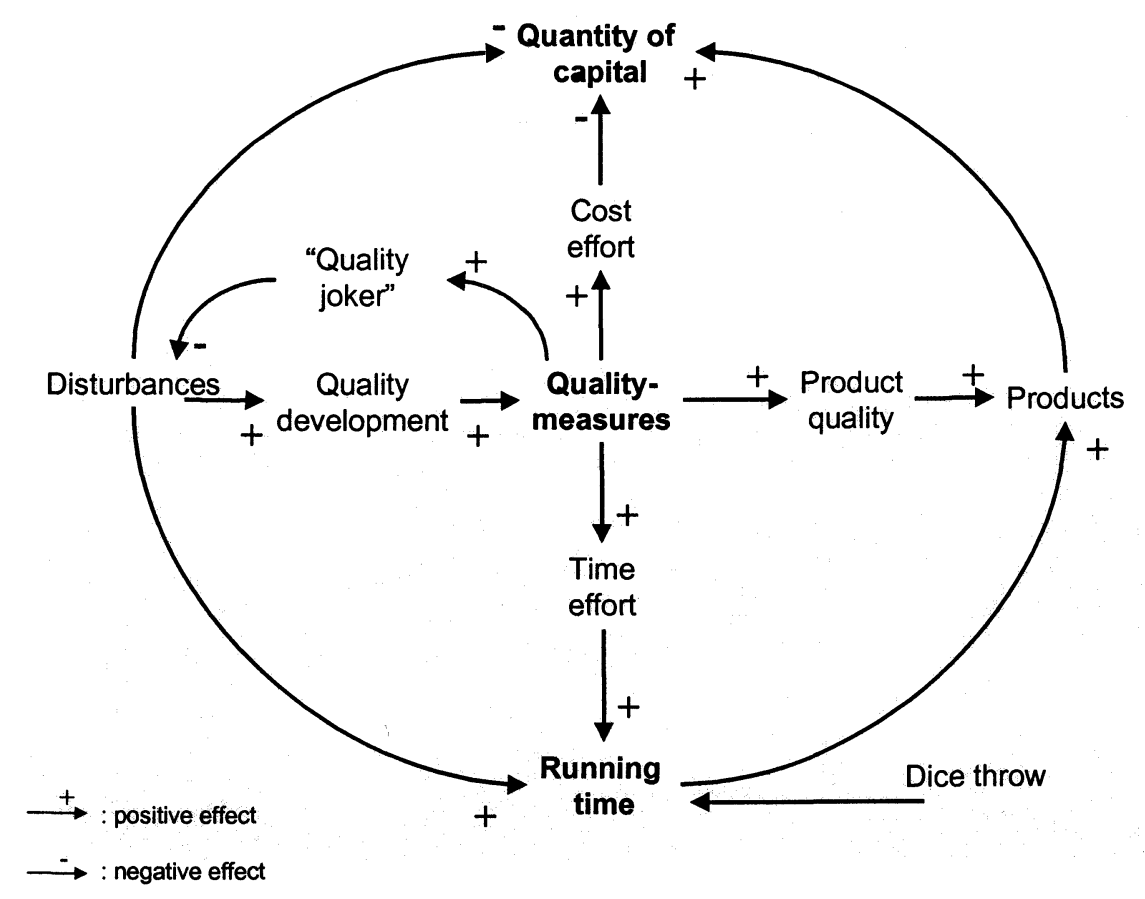

Figure 4. The relationship of quality, costs and time within the simulation game "Q-Key"

Each of the five groups (which each consist of 2 or more persons) is assigned the task to manage one department of a fictitious company. Through the constellation of the departmental mix, employees should, on the one hand, gather experiences through an exchange of roles (from reality to the game), and, on the other hand, they should learn the problems of other departments in the simulation game.

Products, represented by chips, are to be circulated through each department as quickly as possible, whilst preserving a high level of quality and a minimal level of costs. The passage of the products is determined by both the throwing the die and the decisions made by other participants. The products may hit certain squares which stand for external events, taken from the everyday routine of SMEs. In these cases, participants have to react to them by making decisions. 
These event squares are separated into departmental-specific and enterprise-specific events. For both spheres, the events are taken out of the everyday life of SMEs. In this way, the connections in the emergence of quality are shown to the participants of the simulation game. The enterprisespecific events serve to show the repercussions within the enterprise as a whole, as well as to promote team-working.

The participants can protect their departments against the various effects of these external events by carrying out suitable QM measures. By doing so, participants can get hold of trump-cards, the so-called "Quality-Jokers", which enable them to protect their department from various external events. An example would be having to leave the game due to a considerable decrease in quality, which might affect the department in question or the enterprise as a whole in a negative way.

Figure 5 shows the development of "Q-Key" within an enterprise. In the case of the toy car manufacturer, the implementation of Q-Key began with an initial discussion with the management. The previous distribution of the simulation game instructions to the participants proved to be advantageous. The description and explanation of the simulation game by the game organizers could therefore be kept relatively short.

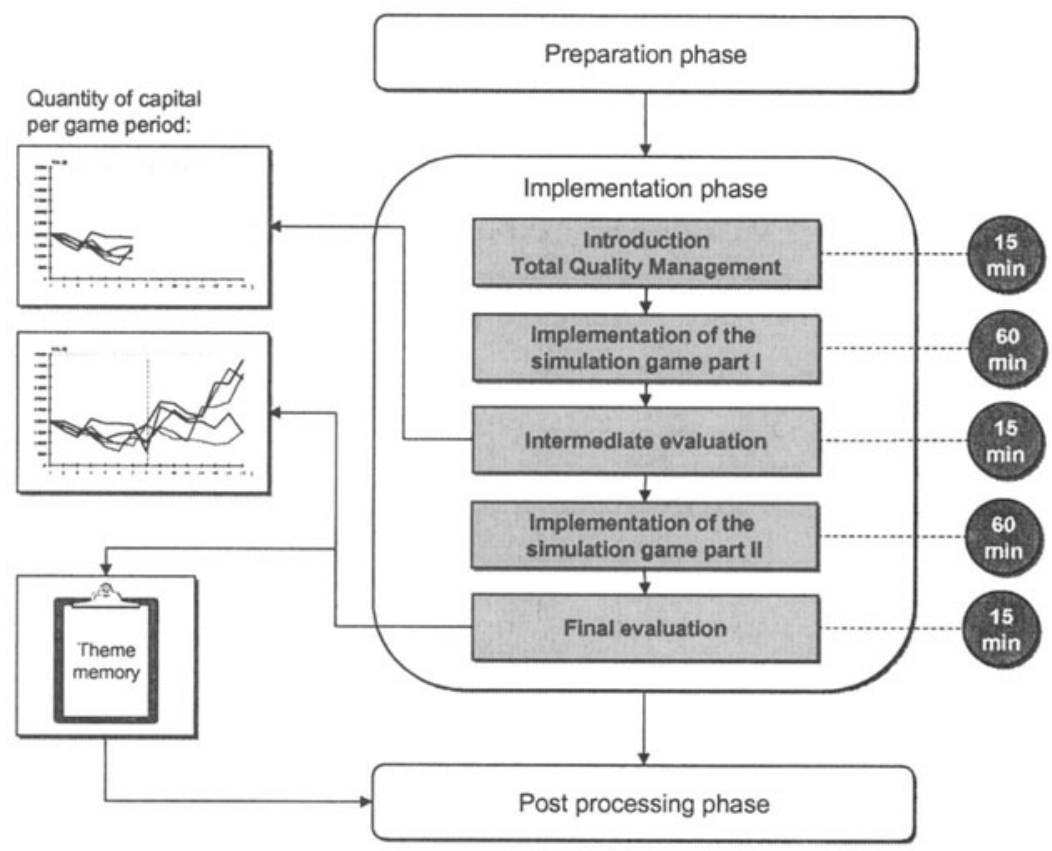

Figure 5. Development of the simulation game "Q-Key - Quality Management" within an enterprise 
The game organizers consisted of two moderators, who were decisive participants in the development of the simulation game. It proved to be sensible when sharing the tasks: one moderator was in charge of the "bank" and documented the course of capital in the different departments, while the other moderator coordinated the allocation of jokers. Both used their respective opportunities to intervene in the events of the simulation game.

Then follows the first phase of play. The players find themselves in a situation of competition; each group attempts to bring results to their department, which has repercussions on the others. In this example, the "procurement" department was an exception: these participants had the highest capital stock in this phase of play. They had tried, through the relinquishment of QM-measures, and through moving as swiftly as possible through the department, to gain as much capital as possible. They succeeded to do this in the first phase.

During the break, there is usually an assumption of a new hypothesis about the game model. Triggered by mutual reflections about the course of the game and the explanation of the coordinator, a situation of co-operation is favored to a situation of competition.

In the example, the marketing/service, development/construction and production departments showed typical courses of capital within the simulation game (shown in Fig. 6). Here the achievement of results from introduced QM measures (especially in the second phase of play) can be seen after the clear fall in capital during the first phase of play. The departments were better protected from events through their jokers, and could achieve higher income through high quality products.

The simulation game is concepted so that the participants' increased willingness to co-operate leads to a better result for the enterprise. In the last phase, the own learning is the most important factor. The participants discuss, under instructions, what learning processes have taken place and how these can be transferred to their own enterprise situation.

In the example, the "distribution" department only introduced very few measures during the course of the whole simulation game and appeared unable to decide for any strategy. Consequently, the course of capital had a slightly negative tendency. The "procurement" department were in the lead after the first phase of play, as they had completely abandoned any QM measures. It was their aim to bring their products as quickly as possible to the target square. This strategy led to the highest stock of capital only until the break, due to the formation of the simulation game. After the break, the QM measures become increasingly important for the departments to gain capital, and finally led to success.

The task of the participating groups is to lead the products, which are symbolized by the corresponding game figures, through the different 
departments, which are under the charge of the employees. The "magic triangle" of quality, time and costs should be taken into consideration by the players. This means that within the simulation game, the participants must attempt to lead their products through their departments whilst maintaining a high level of quality (QM measures should be introduced), but within a reasonable space of time (the game figures should be moved through the departments in the quickest possible time) and with minimal costs (the level of capital should increase). The passage of the products through the departments is determined by both the throwing of the die and the decisions made by the other participants.

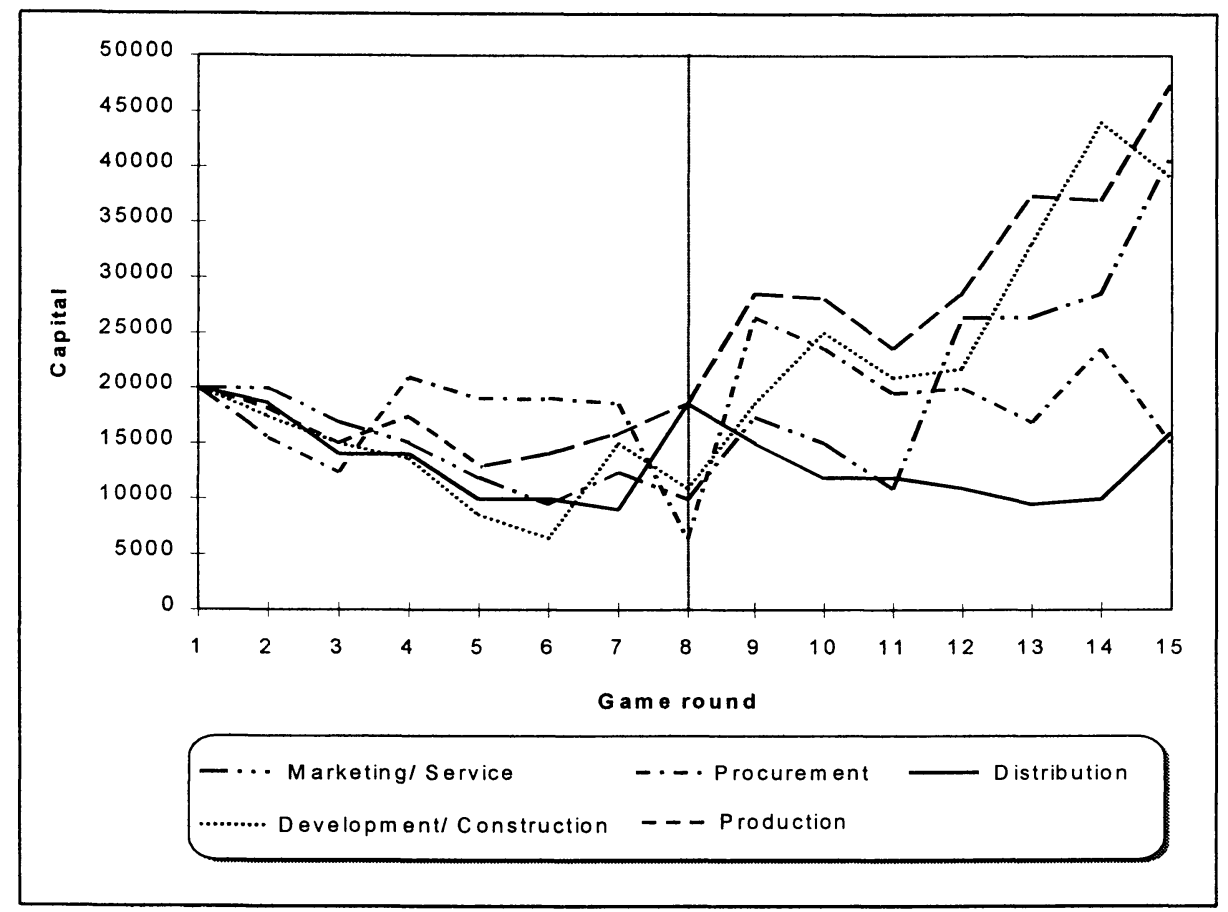

Figure 6. The course of capital in each department within the simulation game "Q-Key" 
Figure 7 portrays some individual characteristics of the three learning levels in Q-Key.

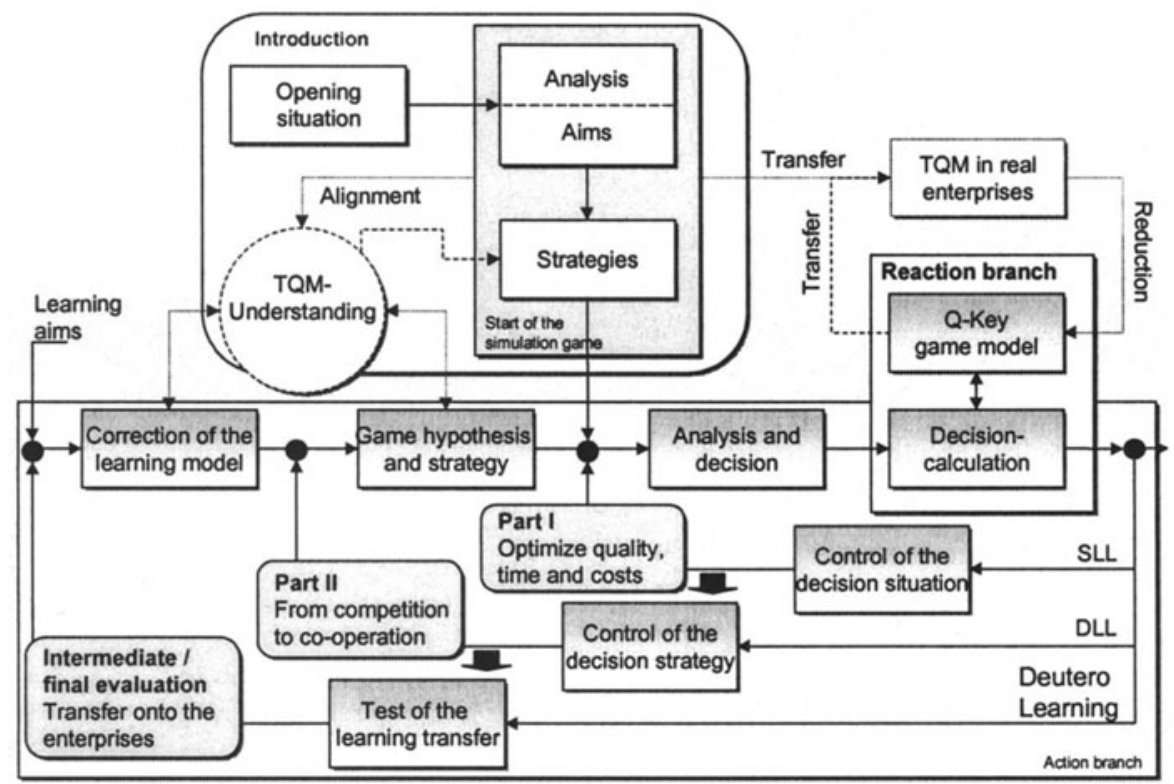

Figure 7: The three learning levels within the board simulation game "QKey"

Result-oriented learning is determined through the central task of the optimization of quality, time and costs. Experience-oriented learning takes place in the questioning of whether the correct hypothesis about the game model (competition vs. co-operation) has been implemented. The third level - transfer-oriented learning - exists in the reflection and transfer of the learning process.

The optimization of the magic triangle of quality, costs and time requires the solution of complex decision processes by the participants. On the basis of their hypothesis of the game, every game decision (Which product do I move forward with the throwing of the die? Should I introduce any measures? Which square should I move to?) must be considered and correspondingly evaluated. Through this, the decision and action behavior of participants is trained, and result-oriented learning is supported.

The players will recognize after a couple of rounds that in order to protect against department-comprehensive events, an agreement with other departments is necessary. Through this recognition, the hypothesis about the game model will adapt during the game. The game is laid out, so that the participants have the opportunity of introducing interaction games (guessing 
of terms from the QM sphere) with other departments. Through the new hypothesis about the game model, participants introduce more interaction games despite increasing costs and time. In the midst of this, willingness to co-operate and communicate is encouraged.

Transfer-oriented learning occurs during the whole course of the game. This is achieved by real measures, daily operational events and consequences determining the contents of the game, whereby the immediate reference to practice is made at all times. It is the task of the game coordinator at the end of the game to pick up on this knowledge and to integrate it into the discussion about the course of the game. The transfer is only sustained when the learning process itself is the object of discussion (What was learnt? How was it learnt? What were the "Aha" effects of the game? etc.).

For the support of transfer-oriented learning, breaks in the course of the game are intended, for example in the form of small of pauses for discussion, to be implemented by the game coordinator. The breaks should give the participants an opportunity to take a "helicopter perspective" look at their learning processes. Just the reflection about learning contents and behavior facilitates the back-up transfer to real learning processes in enterprises.

Finally, it can be said, that all the elements of the three-level-model can be discovered in "Q-Key". In the process, the conscious construction of the three levels supports the sustainability of the learning success way beyond the course of the simulation game.

In the example at the toy car manufacturer, the simulation game was introduced at a relatively late stage. The enterprise already had the ISO 9001 certificate and the employees were correspondingly educated in the simulation game branches. Despite the existing high level of training and motivation of the employees, the simulation game could lead to further improvements. In particular, the mutually-reached understanding of TQM and the conflict of aims which is presents - best prepared the participants for the change process within the enterprise.

\section{Conclusion}

In view of the fact that the survival ability of enterprises depends substantially on their innovativeness, the learning capability of an enterprise is a key factor. The high speed of change in the enterprise environment, and the impossibility to forecast which is linked to it, can only be counteracted by continual improvement and learning processes. In order to be able to react flexibly to the continually changing problems, employees must "learn to learn" (Probst/Gomez, 1989). 
Simulation games train the learning behavior of participants, in which they permanently revise decision processes and are continually presented by new decision problems. Above all, board and hand-oriented simulation games can, under the consideration of the complexity of current enterprise processes, be used to make learning processes easier through action-oriented learning and learning from one's own mistakes.

The three-level model which was presented shows that the teaching method of the simulation game encapsulates all three types of learning within an enterprise (SLL, DLL and Deutero learning). The simulation game is suitable for the systematic improvement of learning capability of individual employees, groups and teams, as well as organizations. The learning processes can more or less be reflectively supported by the game coordinator. Only when it succeeds to create a real learning field out of the playing field of the simulation game, which eventually also seizes the real working field, can the simulation game be a real instrument for the "learning enterprise" of the future.

\section{REFERENCES}

Argyris, C. ; Schön, D. A.(1978) Organizational Learning - a Theory of Action Perspective, Reading Mass. : Addison Wesley

Foerster, H. (1993) Wissen und Gewissen: Versuch einer Brücke, S. Schmidt (Hrsg.), Frankfurt am Main: Suhrkamp

Harramach, N. (1992) Das Management-Plan-Spiel-Buch, Wien: Signum-Verlag

Heidack Heidack, C. (1995) : Lernpotential und Lernfeld "Planspiel". in: Geilhardt / Mühlbradt [Planspiele]

IfU Institut für Unternehmenskybernetik (IfU) e. V. : Projektabschlußbericht - „Erzeugung von Qualitätsbewußtsein und -motivation durch prozeßorientierte Planspiele für kleine und mittlere Unternehmen“. Ülheim 1998.

Probst, G. and P. Gomez (1989). Vernetztes Denken - Unternehmen ganzheitlich führen, Wiesbaden: Gabler

Probst, G. and B. Büchel (1994) Organisationales Lernen - Wettbewerbsvorteil der Zukunft, Wiesbaden: Betriebswirtschaftlicher Verlag Gabler

Reinhardt, R. and P. Pawlowsky (1998) Unternehmensplanspiele und Simulationen als Instrumente zur Unterstützung eines organisationalen Wissensmanagements: Eine theoretische Analyse, TU Chemnitz 


\section{BIOGRAPHY}

\section{Klaus Henning}

Klaus Henning was born in 1945 at Göppingen (German Citizenship). He graduated in electronic engineering at the University of Technology, Munich in 1971.

$\mathrm{He}$ obtained his $\mathrm{PhD}$ in Engineering at the University of Technology, Aachen in 1974, based on his research in human-machine-systems.

His post-doctoral thesis was acknowledged by the University of Technology, Aachen, in 1980. Its theme was "Entropy in Systems Theory".

Since 1985, Dr. Henning is professor and Head of the Centre for research and Development in Higher Education (HDZ), University of technology, RWTH Aachen.

Since 1994 he is in parallel Head of the Department of Computer Science in Mechanical Engineering (IMA),RWTH Aachen, and of the Institute of Entrepreneurial Cybernetics (IfU) in Mülheim/Ruhr.

\section{Sven Haferkamp}

Sven Haferkamp was born in 1966 in Munich (German Citizenship). He graduated in mechanical engineering at the University of Technology, Aachen in 1994. He obtained his Master of Arts Degree in Anglo-American Literature and Linguistics at the University of Technology, Aachen in 1997. Since 1995 he is employed as an engineer and PHD candidate at the Institute of Entrepreneurial Cybernetics (IfU) in Mülheim/Ruhr. The theme of his doctoral thesis is "Development and Application of a (Board) Management Game for the Participative Qualitymanagement in Enterprises":

\section{Siân Thomas}

Siân Thomas was born in 1978 in Cardiff, Wales. She is studying Economy and German at the University Nottingham.

From September 1998 to June 1999 she did a period of practical training at the Institute of Cybernetics (IfU) in Mülheim/Ruhr. 